\title{
EL MERCADO INTERNACIONAL DE LA MIEL DE ABEJA Y LA COMPETITIVIDAD DE MÉXICO
}

\section{THE INTERNATIONAL MARKET FOR HONEY AND THE COMPETITIVENESS OF MEXICO}

Melchor Campos García mcgarcia@correo.uady.mx

FACULTAD DE ECONOMÍA,

UNIVERSIDAD AUTÓNOMA DE YuCATÁn, MÉXICO
Carlos Leyva Morales clmoral@correo.uady.mx FACUlTAd DE ECONOMÍA, UNIVERSIDAD AUTÓNOMA DE YuCATÁN, MÉXICO
María Ferráez Puc

Yuridiamayrany Sánchez Bolívar

FACULTAD DE ECONOMÍA, UNIVERSIDAD AUTÓNOMA DE YuCATÁN, MÉXICO

\section{RESUMEN}

Se analiza el nivel y la tendencia de la competitividad de la miel de abeja de México frente a la oferta externa de excedentes de los principales países productores, durante el periodo 2001-2011. Se utilizó un diseño no experimental longitudinal, en su variante de análisis de tendencia, mediante una revisión de literatura (INEGI, SAGARPA, FAOSTAT), aplicando los indicadores de competitividad del Instituto Interamericano de Cooperación para la Agricultura de Colombia. Se encontró que la producción y el consumo mundial de miel fueron favorables, crecieron en promedio $2.15 \%$ y $2.18 \%$ respectivamente; respecto a la competitividad Argentina ocupó, de acuerdo con índice de transabilidad, el primer lugar; el de balanza comercial relativa posicionó a República Dominicana como primero; en tanto que el de especialización internacional dió a China y Argentina $\left(1^{\circ}\right.$ y $2^{\circ}$ productor) esta posición. La producción de México fue ascendente, igual que su exportación, pero su demanda de importaciones fue descendente; por ello su balanza comercial resultó superavitaria. Se deduce que la tendencia 
favorable observada en el mercado mundial de la miel de abeja de 2001 a 2011 sí se reflejó en México, evidenciándose en el más alto nivel de competitividad de la miel nacional en el mundo, $9^{\circ}$ en índice de transabilidad y de balanza comercial y $3^{\circ}$ en especialización internacional, sólo superado por China y Argentina.

Palabras clave: mercado internacional, balanza comercial, competitividad, miel de abeja, México

Clasificación JEL: C82, E21 y 23, F14, Q11 y 17.

\begin{abstract}
It's analysed the level and trend of Mexico honey bee's competitiveness against the external offer of surpluses of the main producing countries during the 2001-2011 period. A longitudinal non-experimental design was used in its trend analyses variant through a review of literature (INEGI, SAGARPA, FAOSTAT), applying the Inter-American Institute for Cooperation on Agriculture of Colombia's indicators of competitiveness. It was found that the production and world consumption of honney were favorable, they grew on average $2.15 \%$ and $2.18 \%$ respectively, and that in terms of competitiveness, Argentina ranked first, according to the transability index; the relative trade balance index positioned Dominican Republic as first; whereas the international specialization index gave to China and Argentina (1st and 2nd producer) this position. Mexico's production was upward, as was its export, but its demand for imports was donward; for this reason, its trade balance turned out to be surplus. It can be deduced that the favorable trend observed in the world market of honey bee from 2001 to 2011 was reflected in Mexico, evidencing the highest level of competitiveness in the world of the national honey, 9th in transability and trade balance indexes and 3rd in international specialization, second only to China and Argentina.
\end{abstract}

Keywords: international market, trade balance, competitiveness, honey, Mexico. 
Recepción: 1 de septiembre de 2016

Aceptación: 30 de mayo de 2018

\section{INTRODUCCIÓN}

De la misma manera que en otros productos pecuarios, el mercado mundial de miel de abeja muestra una importante concentración, tanto a nivel de oferentes como de demandantes y su producción un crecimiento sostenido y consistente (Soto, Elizarrarás y Soto, 2017). De acuerdo con datos de la Organización de las Naciones Unidas para la Alimentación y la Agricultura (FAO) a nivel mundial tradicionalmente cinco países han concentrado $50 \%$ del total de la producción de miel (China, Argentina, Turquía, Estados Unidos y Ucrania), el principal continente productor es Asia, seguido de Europa y América. China históricamente ha sido el principal país productor con una participación de $22 \%$ del total y además el primer exportador. En 2012, la producción mundial de miel de abeja alcanzó 1,592.70 miles de toneladas, de las cuales China concentró $27.4 \%$ del total, seguido por Turquía con $5.53 \%$, Argentina $4.75 \%$, Ucrania $4.40 \%$ y Estados Unidos $4.19 \%$. En ese año, México fue el octavo productor mundial, con 3.68\% (FAO, 2013).

Por su parte, el comercio mundial de la miel creció 13\% para el año 2011 con respecto al año anterior. Las exportaciones totalizaron $1.6 \mathrm{mil}$ millones de dólares en valor (crecieron 11\%), equivalente a 473 mil toneladas. Las importaciones mundiales de miel aumentaron $15 \%$ para ese año, alcanzando un total de 1.6 mil millones de dólares, equivalente a 484 mil toneladas (Instituto Boliviano de Comercio Exterior, 2012). Los principales importadores del endulzante en 2011 fueron: Estados Unidos con 130,495 toneladas, Alemania con 77,361 y Japón con 40,584 toneladas; le siguieron en importancia Reino Unido, Francia, Bélgica, España e Italia. Estados Unidos desde el 2010 encabeza el ranking como el primer país importador de miel, aunque en años anteriores figuraba Alemania como el principal comprador (FAO, 2013).

La apicultura en México es una actividad que se practica desde hace varias centurias y en la actualidad ha adquirido gran relevancia 
socioeconómica, ya que representa una fuente muy importante de empleos e ingresos en el medio rural (Magaña et al., 2007) y de divisas para el país (Soto, Elizarrarás y Soto, 2017). De acuerdo con las cifras de la Organización de las Naciones Unidas para la Alimentación y la Agricultura (2013), en 2012 México ocupaba el sexto lugar en producción y el tercero en exportación mundial de miel, las principales entidades productoras en ese entonces eran Yucatán, con 10 mil toneladas; Campeche, 7,500; Jalisco, 6,140; Chiapas, 4,600 y Veracruz, con 4,400 toneladas. Y si bien hasta hace dos décadas la mayor parte de la producción de miel del país se destinaba al mercado internacional (76.8 \%) esta tendencia ha cambiado, ya que en la actualidad poco más de la mitad (52\%) de la producción se comercializa en el mercado interno (Magaña et al, 2012).

A fin de colaborar en el análisis de las exportaciones de miel de abeja de México y de su posición competitiva en el mercado mundial, se buscó valorar en forma cuantitativa el nivel y la tendencia de su competitividad frente a la oferta externa de excedentes de los principales países productores. El artículo se encuentra estructurado de la siguiente forma: en el apartado dos se presenta el marco teórico que sustenta el trabajo, en el tercero se establece la metodología utitlizada, donde se explican las técnicas e instrumentos de investigación empleados, así como los principios en que basó el análisis de las variables de ínterés, en el cuarto apartado se incluyen los resultados obtenidos y la discusión de los mismos, se finaliza el documento con la presentación de las conclusiones.

\section{MARCO TEÓRICO}

Sobre el concepto de competitividad internacional se han presentado muchos disensos. Al respecto Krugman (1997) argumenta que aplicar el concepto de competitividad a una economía nacional en el mismo sentido en que compiten las empresas es erroneo: una empresa no competitiva quiere decir que su posición en el mercado es insostenible y que si no mejora su funcionamiento, dejará de existir, sin embargo, los países no cierran aunque sean infelices por su situación económica, dado que la mayor parte de 
su producción doméstica se "realiza" en el mercado interno y depende de los desarrollos tecnológicos, productivos y organizacionales. A esto hay que adicionar que los resultados de la especialización y la competitividad entre países son más vigorosos cuando orientan sus esfuerzos en función de la estructura del mercado y cuando los beneficios dependen de la forma como evolucione él mismo. Por ello, en la actualidad se entiende por competitividad a la capacidad de una organización económica (empresa, eslabón o cadena productiva) para mantener, conquistar o ampliar su participación en el mercado, incluido el interno, de una manera rentable que permita su crecimiento y sea sostenible en el largo plazo. En otras palabras, la competitividad es un concepto dinámico cuyo logro o preservación implica la incorporación de progreso técnico, es decir, del tránsito hacia nuevas funciones de producción (Instituto Interamericano de Cooperación para la Agricultura, 2005). Asimismo, la competitividad en el mercado internacional depende de diversas variables que se entrelazan de distintas formas de acuerdo con el tipo de mercancía de que se trate, encontrándose entre las más importantes: la dotación de factores de la producción y su diferencia en costos relativos que da origen a ventajas comparativas; el dominio y control de una característica, habilidad, recurso o conocimiento que permita distanciarse de la competencia y generar ventajas competitivas; la estacionalidad de la mercancía (sobre todo tratándose de productos agropecuarios); los costos de transporte y comercialización; las barreras arancelarias y no arancelarias; los movimientos en el tipo de cambio y las políticas públicas de los países de origén y destino, incluyendo las de tipo transnacional. Además de que debe de integrar las perspectivas territoriales en su estudio, la internacional y la regional, poniéndolas en el marco de la geografía económica para enriquecer su ejercicio teórico y empírico con la robustez de esta disciplina (Macías, 2010).

El otro compornente de importancia en un análisis de competitividad lo contituye el mercado, el cual de acuerdo con Parkin y Loría (2010) es un lugar o situación en la que se compran y venden bienes, servicios y factores y en donde la cantidad que se comercializa varía según el precio, por lo tanto, la proyección de respuestas de los compradores ante cambios en los precios se llama demanda y la de los vendedores se denomina oferta. Sin 
embargo, la delimitación de un mercado es un proceso complejo que implica estudiar las condiciones que impone la demanda de un lado (consumo más importaciones), es decir, la zona de decisión del consumidor respecto a un producto. Además, de la oferta (producción más exportaciones), la cual requiere conocer su estructura (el contenido), que tiene que ver principalmente con la distribución por tamaño de las firmas competidoras. En este contexto Parkin y Loría señalan que los tres elementos de análisis que determinan el tipo de estructura de mercado en que se compite serán: la cuota de mercado, es decir, su participación en este como porcentaje de las ventas totales de determinada industria o sector, indicador que reviste importancia para definir si existe monopolio; la concentración y número de rivales comparables, la primera porque es una medida que hace evidente el grado de oligopolio, en tanto que el número de rivales puede ser decisivo, no así la cantidad total de firmas competidoras en el mercado; por último, las condiciones para el ingreso o barreras que afecten la capacidad de competidores potenciales que se hallan fuera del mercado para entrar y convertirse en competidores de hecho (cualquier cosa que disminuya la probabilidad, el alcance o la velocidad de acceso de otras firmas).

En cuanto a los trabajos más recientes disponibles sobre competitividad de la miel, entre estos se encuentran el de Antequera y Guido (2007) que analiza la posición de Nicaragua en el contexto mundial en el periodo 2002-2006; la tesis de maestría de Antequera (2015), en donde la autora evalua lo posición de Nicaragua y sus socios comerciales en el mercado centroamericano de 2007 a 2013 y el trabajo de Magaña et al. (2017) que analiza la posición competitiva de México en el contexto mundial en el periodo 2000-2011. Todos ellos basados en la aplicación del cálculo de los índices de transabilidad, de balanza comercial relativa y de especializacion internacional, que constituyen la base de la metodología propuesta por el Instituto Interamericano de Cooperación para la Agricultura (IICA) de Colombia para medir este indicador económico. Los tres índices citados se decriben a continuación:

El primero de ellos, el indicador de transabilidad, mide la relación entre la balanza comercial neta y el consumo aparente, esto es, la participación de las exportaciones o las importaciones en el consumo de un país. Si 
es mayor que cero, la actividad se considera exportadora, dado que existe un exceso de oferta y el producto es competitivo en el mercado interno. Pero si es menor que cero, entonces se trata de un producto importable y que no es competitivo en el mercado interno, dado que existe un exceso de demanda.

Los indicadores auxiliares de este indicador son:

a)Grado de apertura exportadora (GE), el cual indica el grado en que las exportaciones de un producto con respecto a su consumo aparente penetran en un mercado. Si en un periodo de varios años, el indicador se acerca a cero, la competitividad del país con respecto a sus competidores está cayendo, ya que no existe la capacidad de sobrepasar el nivel de producción necesario para abastecer la demanda interna. b)Grado de penetración de importaciones (GI), muestra la relación entre las importaciones de un bien o sector y su consumo doméstico aparente. Si su valor se acerca a cero, el sector es lo suficientemente competitivo como para dedicar gran parte de la producción nacional a la exportación. Sin embargo, deben considerarse las restricciones de política comercial, Ministerio de Agricultura y Desarrollo Rural (s.f.). La balanza comercial relativa (indicador intrarama o intraproducto), se interpreta como un índice de ventaja competitiva que se presenta cuando un sector exporta más de lo que importa, caso en el cual el índice presenta un valor positivo. Si es un sector totalmente orientado a la exportación el valor del índice será de $100 \%$, por el contrario, si se orienta a la importación será de $-100 \%$. Asimismo, si es mayor que cero, se trata de un sector exportador y por ende, competitivo. Si es menor que cero, se trata de un sector importador y carente de competitividad frente al mercado externo.

c)En tanto que el indicador de especialización internacional mide la participación del saldo de la balanza comercial de un producto en el total de las exportaciones mundiales, por lo cual permite examinar la vocación exportadora de cada país y la capacidad del mismo para construir ventajas competitivas permanentes. Cuando el valor del indicador es de $100 \%$, significa que el país en cuestión es el único exportador mundial $\mathrm{y}$, en consecuencia, tiene una alta especialización 
internacional en el producto de interés; pero cuando este valor es negativo, significa que no hay ningún grado de especialización y el país presenta dificultades competitivas, Ministerio de Agricultura y Desarrollo Rural (s.f.).

\section{METODOLOGÍA}

Las técnicas e instrumentos en los que se sustentó el estudio fueron una revisión de literatura de diferentes fuentes de información secundarias disponibles en la entidad (Secretaría de Agricultura, Ganadería, Desarrollo Rural, Pesca y Alimentación, Sagarpa y el Instituo Nacional de Estadística y Geografía, INEGI), así como de las existentes en los bancos de información disponibles en internet (FAOSTAT, de la Organización para la Alimentación y la Agricultura). En tanto que en la recolección de la información básica se utilizó como instrumento una bitácora de trabajo, en la que se consideraron los siguientes apartados de información: producción y oferta mundial de miel de abeja, producción nacional, consumo y demanda mundial de miel, consumo nacional, exportación e importación de miel en el mercado mundial y exportación e importación en el mercado nacional.

La información recopilada se ordenó, clasificó y procesó por medio de una hoja de cálculo electrónica (Excel), la cual permitió la estimación de los coeficientes estadísticos e indicadores matemáticos de comportamiento (Kasmier, 2006) planteados para el estudio (valores promedio y tasas de cambio), así como el posterior análisis de las variables económicas consideradas con base en los principios sobre el estudio de la economía de mercado propuestos por Parkin y Loría (2010).

Asimismo, se estimaron y jerarquizaron los indicadores de competitividad de los 50 principales países productores de miel de abeja en el mundo empleándose la base de datos de FAOSTAT y comprende el periodo de 2001 a 2011. Su análisis se fundamentó en el enfoque de la competitividad del IICA de Colombia y, por ello, se midieron y analizaron los índices asociados al nivel de competitividad internacional del 
producto considerado (Roldán, 2000). Las fórmulas para el cálculo de cada uno de los indicadores señalados fueron:

El indicador de transabilidad se midió mediante la fórmula: Tij = $(\mathrm{Xij}-\mathrm{Mij}) /(\mathrm{Qij}+\mathrm{Mij}-\mathrm{Xij})$

Donde: $\mathrm{Xij}=$ exportaciones del producto i del país $\mathrm{j}$.

Mij = importaciones del producto i del país j.

Qij = producción doméstica del producto i del país j.

En tanto que sus indicadores auxiliares se calcularon mediante las dos siguientes expresiones: $\mathrm{GE}=\mathrm{Xij} /(\mathrm{Qij}+\mathrm{Mij}-\mathrm{Xij})$, con un rango de variación: entre 0 y 1 ; y el GI $=$ Mij / (Qij + Mij - Xij $)$ con un rango: entre 0 y 1.

La balanza comercial relativa se representó de forma algebraica como: $\mathrm{BC}=(\mathrm{Xij}-\mathrm{Mij}) /(\mathrm{Xij}+\mathrm{Mij})$

Donde: $\mathrm{Xij}=$ exportaciones de un producto i por un país $\mathrm{j}$ al mercado mundial o un mercado específico.

Mij = importaciones de un producto i por un país al mercado mundial o un mercado específico.

Rango de variación: entre -1 y 1 .

Y el indicador de especialización internacional se obtuvo mediante la expresión algebraica:

$\mathrm{IE}=(\mathrm{Xij}-\mathrm{Mij}) /(\mathrm{Xim})$

Donde: $\mathrm{Xij}=$ Exportaciones del bien i realizadas por el país $\mathrm{j}$.

Mij = Importaciones del bien i realizadas por el país j.

Xim $=$ Exportaciones del bien i realizadas por el mundo o un mercado específico.

Rango: entre -1 y 1 (Ministerio de Agricultura y Desarrollo Rural (s.f.)).

\section{TENDENCIAS DE LA PRODUCCIÓN}

El volumen agregado de la producción de miel a nivel mundial a lo largo de los años 2001 al 2011, en general mostró un comportamiento creciente 
y durante este periodo se incrementó $19.06 \%$, al pasar de 1,273.27 miles de toneladas a 1,573.03 (cuadro 1). La tasa de crecimiento media anual de esta producción registró un valor de $2.06 \%$, sin embargo, sus tasas de cambio anuales han tenido un comportamiento irregular, es decir, presentaron tasas de crecimiento significativas, como por ejemplo en los años 2006 (5.81\% , su máximo nivel) y 2008 (3.88\%), así como también tasas decrecientes, como las registradas en los años 2007 y $2009,-2.97 \%$ y $-0.70 \%$, respectivamente.

\section{Cuadro 1}

Producción de miel a nivel mundial

(miles de toneladas)

\begin{tabular}{|c|c|c|}
\hline Años & Producción mundial & Tasa de crecimiento \% \\
\hline 2001 & $1,273.27$ & --- . \\
\hline 2002 & $1,289.77$ & 2.87 \\
\hline 2003 & $1,327.90$ & 2.73 \\
\hline 2004 & $1,365.21$ & 3.71 \\
\hline 2005 & $1,417.86$ & 5.81 \\
\hline 2006 & $1,505.35$ & -2.97 \\
\hline 2007 & $1,461.92$ & 3.88 \\
\hline 2008 & $1,520.96$ & -0.7 \\
\hline 2009 & $1,510.32$ & 2.38 \\
\hline 2010 & $1,547.22$ & 1.64 \\
\hline 2011 & $1,573.03$ & 2.06 \\
\hline \multicolumn{2}{|c|}{ Tasa media de crecimiento } & \\
\hline
\end{tabular}

Fuente: elaboración propia con datos de FAOSTAT, 2013.

El principal país productor de miel de abeja en el mundo es China, que pertenece a la región de Asia, con un total de 446.09 miles de toneladas en el año 2011 y representa $26.4 \%$ de la producción mundial (en 2001 dicho volumen representó sólo $19.8 \%$ de este total), cifras que manifiestan la importancia del país asiático en la producción de miel de abeja en el mundo (cuadro 2). 


\section{Cuadro 2}

Principales países productores de miel de abeja

(miles de toneladas)

\begin{tabular}{|c|c|c|c|c|c|c|c|c|c|c|c|}
\hline Países & 2001 & 2002 & 2003 & 2004 & 2005 & 2006 & 2007 & 2008 & 2009 & 2010 & 2011 \\
\hline China & 254.36 & 267.83 & 294.72 & 297.99 & 299.53 & 337.58 & 357.22 & 407.22 & 407.37 & 409.15 & 446.09 \\
\hline Argentina & 80.00 & 83.00 & 75.00 & 80.00 & 110.00 & 105.00 & 81.00 & 72.00 & 62.00 & 59.00 & 74.00 \\
\hline Turquía & 60.19 & 74.55 & 69.54 & 73.93 & 82.34 & 83.84 & 73.93 & 81.36 & 82.00 & 81.11 & 94.24 \\
\hline $\begin{array}{l}\text { Estados } \\
\text { Unidos }\end{array}$ & 84.33 & 77.89 & 82.43 & 83.27 & 72.93 & 70.24 & 67.29 & 74.29 & 66.41 & 80.04 & 67.29 \\
\hline Ucrania & 60.04 & 51.14 & 53.55 & 57.88 & 71.46 & 75.60 & 67.70 & 74.90 & 74.10 & 70.87 & 40.31 \\
\hline México & 59.07 & 58.89 & 57.04 & 56.92 & 50.63 & 55.97 & 55.46 & 55.27 & 56.07 & 55.68 & 57.78 \\
\hline India & 52.00 & 52.00 & 52.00 & 52.00 & 52.00 & 52.00 & 51.00 & 55.00 & 55.00 & 60.00 & 60.00 \\
\hline $\begin{array}{l}\text { Federa- } \\
\text { ción de } \\
\text { Rusia }\end{array}$ & 52.66 & 49.40 & 48.05 & 52.67 & 52.12 & 55.68 & 53.65 & 57.44 & 53.60 & 51.53 & 60.01 \\
\hline Etiopía & 33.78 & 39.60 & 37.80 & 40.90 & 36.00 & 51.25 & 42.18 & 42.00 & 41.52 & 53.67 & 39.89 \\
\hline Irán & 26.60 & 28.04 & 15.10 & 28.67 & 34.79 & 36.04 & 47.00 & 41.00 & 46.00 & 47.00 & 47.50 \\
\hline Canadá & 35.39 & 37.07 & 34.60 & 34.24 & 36.11 & 48.35 & 31.49 & 29.44 & 31.92 & 33.71 & 35.52 \\
\hline Brasil & 22.22 & 23.99 & 30.02 & 32.29 & 33.75 & 36.19 & 34.75 & 37.79 & 38.97 & 38.02 & 41.60 \\
\hline España & 31.62 & 35.72 & 35.28 & 34.21 & 27.23 & 30.66 & 31.84 & 30.36 & 32.34 & 34.55 & 34.62 \\
\hline $\begin{array}{l}\text { República } \\
\text { Unida de } \\
\text { Tanzania }\end{array}$ & 26.50 & 26.50 & 27.00 & 27.50 & 27.50 & 28.00 & 27.50 & 27.00 & 28.00 & 28.50 & 28.00 \\
\hline Angola & 24.00 & 25.32 & 23.00 & 21.56 & 24.00 & 23.00 & 25.56 & 26.58 & 25.56 & 22.90 & 22.90 \\
\hline Mundo & $1,273.27$ & $1,289.77$ & $1,327.90$ & $1,365.21$ & $1,417.86$ & $1,505.35$ & $1,461.92$ & $1,520.96$ & $1,510.32$ & 1547.22 & $1,573.03$ \\
\hline
\end{tabular}

Fuente: elaboración propia con datos de FAOSTAT, 2013.

En total el volumen de producción de miel de China se incrementó en 191.73 miles de toneladas del año 2001 al 2011, registró una tasa media de crecimiento anual de 5.9\%, no fue el caso de Turquía, Estados Unidos y Ucrania, tercer, cuarto y quinto productor, quienes registraron tasas inferiores, de 5.0, -1.67 y $-2.11 \%$, respectivamente. Después de China, el segundo país en importancia en cuanto a su aportación a la producción mundial de miel de abeja en el año 2011 fue Turquía, con una 
participación de $6 \%$, el resto de países que presentaron una contribución de importancia fueron Argentina, 5\% y Estados Unidos, México, India y la Federación de Rusia, todos ellos, con una aportación de 4\%, respectivamente.

\section{PRODUCCIÓN POR REGIONES}

A nivel mundial, la región de Asia ha sido la mayor productora de miel de abeja, en el año 2011 alcanzó un total de 732.54 miles de toneladas (gráfica 1). En contraste, Oceanía es el continente que ocupa el último lugar en este mercado con una producción de sólo 26.51 miles de toneladas en el mismo año.

\section{Gráfica 1}

Producción de miel por continente

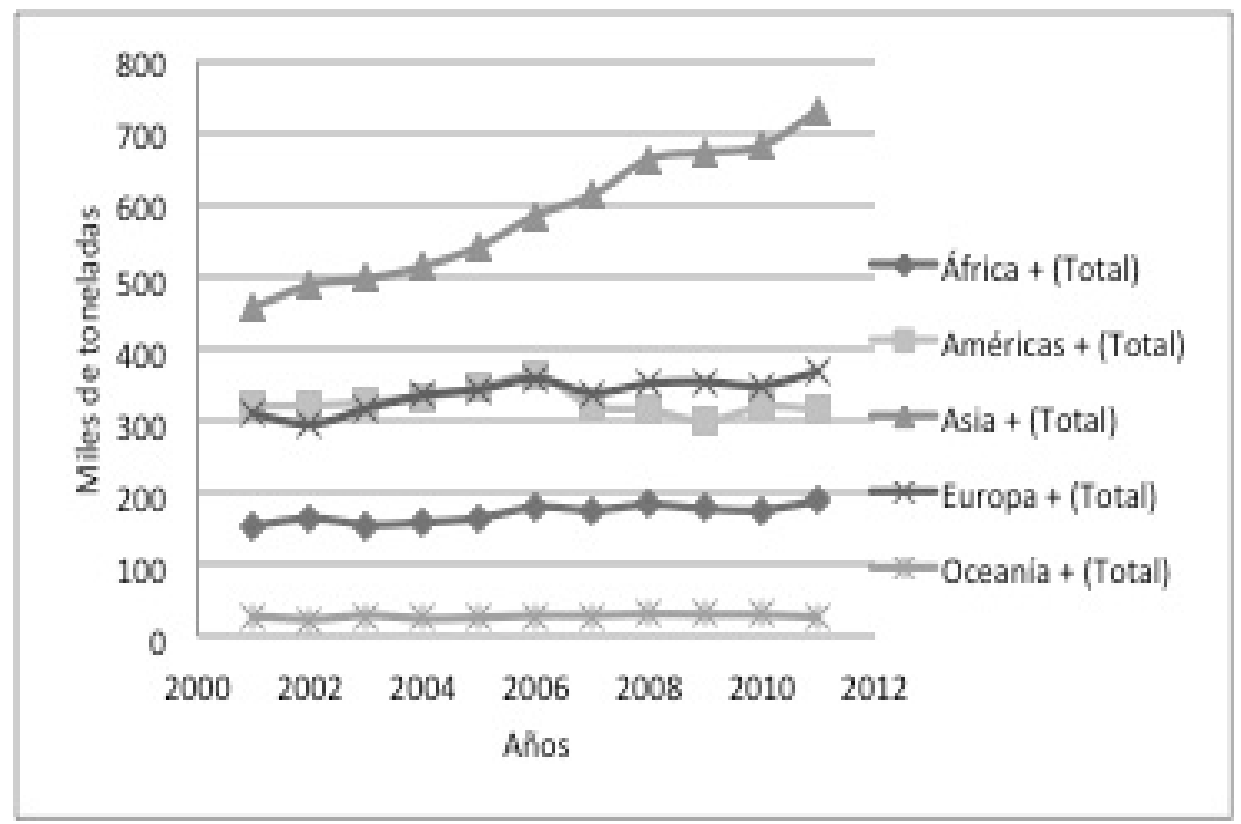

Fuente: elaboración propia con datos de FAOSTAT, 2013. 
La contribución de Asia a la producción de miel de abeja del mundo pasó de $36.01 \%$ en 2001 a $44.87 \%$ en 2011 (cuadro 3) conformándose como la región más dinámica en el ámbito mundial, resultado de su fuerte crecimiento en los últimos tres quinquenios, y abre una gran brecha de distancia con respecto a las otras regiones productoras desde el año 2001. La mayoría de las otras regiones, por su parte, presentaron niveles de participación significativamente menores en la producción total y con una tendencia inclusive decreciente en su contribución (el caso de Oceanía con una disminución de $-28.6 \%$ en el periodo y de América de -23.4\%).

\section{Cuadro 3}

Variación anual de la participación macroregional en la producción de miel de abeja

\begin{tabular}{|c|c|c|c|c|c|c|}
\hline Año/Continente & África & América & Asia & Europa & Oceanía & Mundo \\
\hline 2001 & 12.03 & 25.26 & 36.01 & 24.43 & 2.27 & 100.00 \\
\hline 2002 & 12.70 & 24.87 & 37.86 & 22.77 & 1.80 & 100.00 \\
\hline 2003 & 11.68 & 24.61 & 37.57 & 23.95 & 2.18 & 100.00 \\
\hline 2004 & 11.57 & 24.38 & 37.72 & 24.55 & 1.77 & 100.00 \\
\hline 2005 & 11.56 & 24.30 & 38.19 & 24.15 & 1.81 & 100.00 \\
\hline 2006 & 11.87 & 23.95 & 38.66 & 23.64 & 1.88 & 100.00 \\
\hline 2007 & 11.86 & 21.71 & 41.59 & 22.91 & 1.94 & 100.00 \\
\hline 2008 & 11.85 & 20.40 & 43.00 & 22.77 & 1.98 & 100.00 \\
\hline 2009 & 11.55 & 19.48 & 43.93 & 23.07 & 1.96 & 100.00 \\
\hline 2010 & 11.28 & 20.52 & 43.89 & 22.40 & 1.90 & 100.00 \\
\hline 2011 & 11.54 & 19.36 & 44.87 & 22.60 & 1.62 & 100.00 \\
\hline
\end{tabular}

Fuente: elaboración propia con datos de FAOSTAT, 2013.

El continente Europeo ocupó el segundo lugar en el volumen de producción mundial desde 2007 con 368.95 miles de toneladas en 2011 (participación de $22.6 \%$ del total mundial); sin embargo, esta región registró un comportamiento menos dinámico, con tasas de crecimiento comparativamente más bajas que las de las regiones de Asia y África a lo largo del periodo, incluso en los años 2002, 2007 y 2010 presentó valores negativos (cuadro 4). 


\section{Cuadro 4}

Crecimiento anual de la producción de miel de abeja por región

\begin{tabular}{|c|c|c|c|c|c|c|}
\hline Año/Continente & África & América & Asia & Europa & Oceanía & Mundo \\
\hline 2001 & - & - & - & - & - & - \\
\hline 2002 & 7.38 & 0.16 & 6.98 & -5.15 & -19.16 & 2.34 \\
\hline 2003 & -5.66 & 1.44 & 1.74 & 7.83 & 24.09 & 3.81 \\
\hline 2004 & 2.06 & 2.14 & 3.49 & 5.68 & -16.3 & 2.73 \\
\hline 2005 & 4.01 & 3.75 & 5.41 & 2.4 & 6.14 & 3.48 \\
\hline 2006 & 9.49 & 5.11 & 7.93 & 4.36 & 11.12 & 7.69 \\
\hline 2007 & -2.56 & -11.63 & 4.9 & -5.5 & 0.49 & -0.97 \\
\hline 2008 & 4.45 & -1.75 & 8.07 & 3.91 & 6.7 & 6.37 \\
\hline 2009 & -3.23 & -5.19 & 1.4 & 0.58 & -1.79 & -0.58 \\
\hline 2010 & -0.89 & 6.87 & 1.37 & -1.49 & -1.54 & 1.25 \\
\hline 2011 & 7.33 & -1.01 & 7.25 & 5.83 & -10.47 & 5.77 \\
\hline Tasa Media & 2.23 & -0.01 & 4.86 & 1.84 & -0.07 & 3.18 \\
\hline
\end{tabular}

Fuente: elaboración propia con datos de FAOSTAT, 2013.

Por su parte, la región de América se ubica en el cuarto lugar y se ha caracterizado por presentar una tasa media negativa de crecimiento en su producción, tasa media anual de $-0.01 \%$ (superada por Asia, África y Europa con tasas de $4.86 \%, 2.23 \%$ y $1.84 \%$ respectivamente). De las regiones del continente americano, la región sur (que presentó una burbuja de crecimiento al inicio del periodo y a partir del año 2005 registrar una pendiente negativa y culminar con una producción ligeramente superior a la del año base en 2011) es la que más participación presenta en el periodo (pasó de una contribución de $39.61 \%$ en 2001 a una de 42.8\% en 2011), registró una producción de 135.39 miles de toneladas en el año 2011. En tanto que la menor participación le corresponde al Caribe, con $3.46 \%$ en promedio a lo largo del lapso del lapso analizado (gráfica 2). 


\section{Gráfica 2}

Producción de miel de abeja por región de América

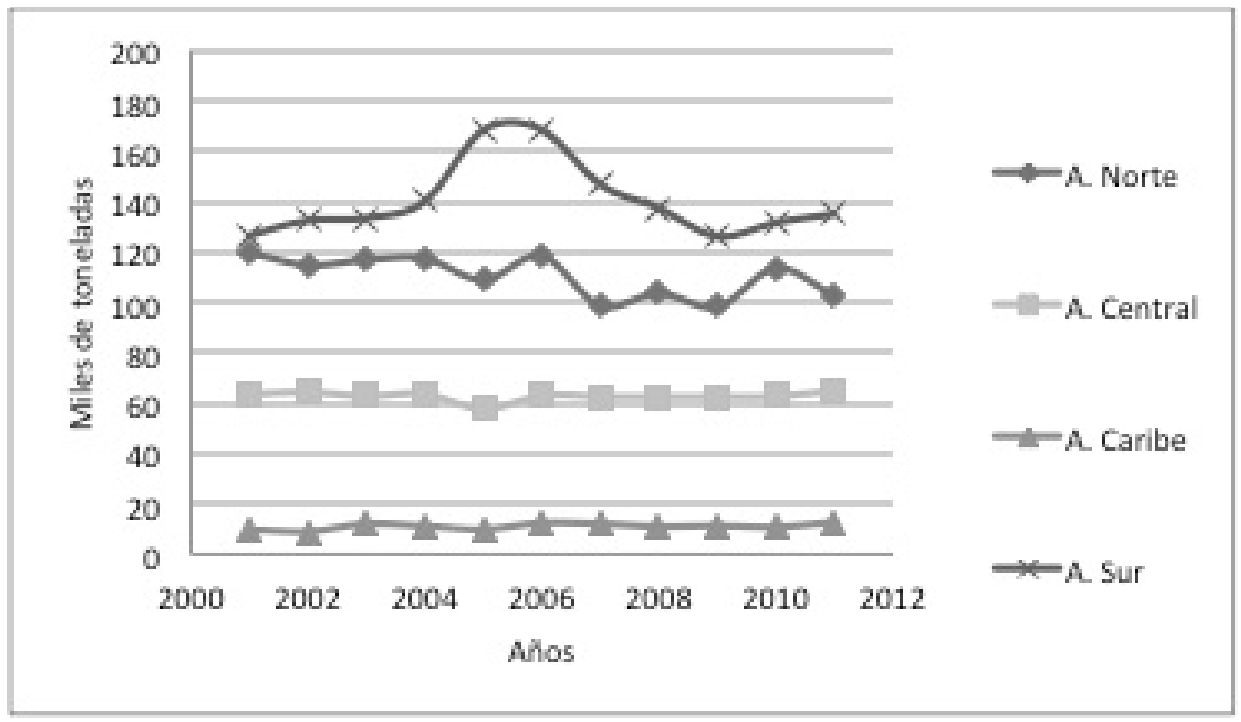

Fuente: elaboración propia con datos de FAOSTAT, 2013.

México se encuentra en la región de América del Norte, zona que se ubica en la segunda posición entre las productoras de miel de América con 102.81 miles de toneladas de producción en el 2011 y con una participación a nivel continente del 32.52\% (cuadro 5).

\section{Cuadro 5}

Participación de América por regiones en la producción mundial de miel de abeja

\begin{tabular}{|c|c|c|c|c|c|}
\hline Año/Continente & A. Norte & A. Central & A. Caribe & A. Sur & Continente \\
\hline 2001 & 37.32 & 19.93 & 3.12 & 39.61 & 100 \\
\hline 2002 & 35.78 & 20.07 & 2.83 & 41.3 & 100 \\
\hline 2003 & 35.91 & 19.31 & 3.74 & 41.03 & 100 \\
\hline 2004 & 35.3 & 19.15 & 3.38 & 42.15 & 100 \\
\hline 2005 & 31.57 & 16.71 & 2.88 & 48.83 & 100 \\
\hline 2006 & 32.66 & 17.39 & 3.46 & 46.47 & 100 \\
\hline 2007 & 30.78 & 19.57 & 3.81 & 45.81 & 100 \\
\hline 2008 & 32.91 & 19.89 & 3.52 & 43.66 & 100 \\
\hline
\end{tabular}




\begin{tabular}{|c|c|c|c|c|c|}
\hline 2009 & 32.9 & 20.99 & 3.81 & 42.28 & 100 \\
\hline 2010 & 35.61 & 19.7 & 3.41 & 41.27 & 100 \\
\hline 2011 & 32.52 & 20.57 & 4.07 & 42.82 & 100 \\
\hline
\end{tabular}

Fuente: elaboración propia con datos de FAOSTAT, 2013.

La región de América del Norte es encabezada por Estados Unidos con montos de producción sobresalientes en el periodo 2001-2011, en el año 2011 alcanzó la cantidad de 67.29 miles de toneladas de miel de abeja (cuadro 6), aunque con una tasa de participación en el total decreciente (cuadro 6). México, por su parte, se encuentra ubicado en el segundo lugar de producción en esta zona (con un total en 2011 de 57.78 miles de toneladas), con una tasa de participación creciente en el periodo, sin embargo, en comparación con los países productores de importancia del continente americano, se situá muy por debajo de Argentina, el principal productor.

\section{Cuadro 6}

Producción de miel de abeja en América del Norte

(miles de toneladas)

\begin{tabular}{|c|c|c|c|c|c|c|c|}
\hline $\begin{array}{c}\text { Años/ } \\
\text { Países }\end{array}$ & Canadá & Participación \% & México & Participación \% & $\begin{array}{c}\text { Estados } \\
\text { Unidos }\end{array}$ & Participación \% & $\begin{array}{c}\text { América } \\
\text { del Norte }\end{array}$ \\
\hline 2001 & 35.39 & 19.79 & 59.07 & 33.03 & 84.33 & 47.17 & 178.79 \\
\hline 2002 & 37.07 & 21.32 & 58.89 & 33.87 & 77.89 & 44.80 & 173.85 \\
\hline 2003 & 34.60 & 19.88 & 57.04 & 32.77 & 82.43 & 47.35 & 174.08 \\
\hline 2004 & 34.24 & 19.63 & 56.92 & 32.63 & 83.27 & 47.74 & 174.43 \\
\hline 2005 & 36.11 & 22.61 & 50.63 & 31.71 & 72.93 & 45.67 & 159.67 \\
\hline 2006 & 48.35 & 27.70 & 55.97 & 32.06 & 70.24 & 40.24 & 174.56 \\
\hline 2007 & 31.49 & 20.42 & 55.46 & 35.96 & 67.29 & 43.62 & 154.23 \\
\hline 2008 & 29.44 & 18.51 & 55.27 & 34.76 & 74.29 & 46.72 & 159.00 \\
\hline 2009 & 31.92 & 20.67 & 56.07 & 36.31 & 66.41 & 43.01 & 154.40 \\
\hline 2010 & 33.71 & 19.89 & 55.68 & 32.86 & 80.04 & 47.24 & 169.44 \\
\hline 2011 & 35.52 & 22.12 & 57.78 & 35.98 & 67.29 & 41.90 & 160.60 \\
\hline
\end{tabular}

Fuente: elaboración propia con datos de FAOSTAT, 2013. 
No obstante lo anterior, la tasa media anual de crecimiento de producción más alta en América del Norte de 2001 a 2011 la registro Canadá con $1.4 \%$, muy superior a la tasa media de crecimiento de América del Norte que fue de $-0.85 \%$ (cuadro 7 ).

\section{Cuadro 7}

Crecimiento de la producción de miel de abeja en América del Norte

\begin{tabular}{|c|c|c|c|c|}
\hline Años/Países & Canadá & México & Estados Unidos & América del Norte \\
\hline 2001 & - & - & - & - \\
\hline 2002 & 4.75 & -0.30 & -7.64 & -2.76 \\
\hline 2003 & -6.66 & -3.13 & 5.83 & 0.13 \\
\hline 2004 & -1.04 & -0.22 & 1.02 & 0.20 \\
\hline 2005 & 5.45 & -11.04 & -12.42 & -8.46 \\
\hline 2006 & 33.90 & 10.54 & -3.68 & 9.32 \\
\hline 2007 & -34.87 & -0.91 & -4.20 & -11.64 \\
\hline 2008 & -6.50 & -0.33 & 10.41 & 3.09 \\
\hline 2009 & 8.42 & 1.44 & -10.60 & -2.89 \\
\hline 2010 & 5.60 & -0.69 & 20.52 & 9.73 \\
\hline 2011 & 5.36 & 3.76 & -15.92 & -5.21 \\
\hline Tasa media & $1.44 \%$ & $-0.09 \%$ & $-1.67 \%$ & $-0.85 \%$ \\
\hline
\end{tabular}

Fuente:elaboración propia con datos de FAOSTAT, 2013.

En el caso de México, su producción de miel en 2001 contribuía a la producción total de América del Norte con 33.03\%, en el año 2009 logró su mayor contribución a la zona con $36.3 \%$; sin embargo, en 2010 disminuyó a sólo $32.8 \%$, recuperándose en 2011 , año donde registra una participación porcentual de 35.9\% (cuadro 8). Este comportamiento en la contribución del país en el total de la producción de miel de América del Norte (incremento de 3\% en el periodo) contrasta con lo sucedido con Estados Unidos, quien registró en ese lapso un decrecimiento en este indicador, al pasar de $47.1 \%$ en 2001 a $41.9 \%$ en 2011 . 


\section{PAIISES EXPORTADORES}

En términos absolutos, la oferta de exportación de miel de abeja en el mercado mundial pasó de 360.95 miles de toneladas en 2001 a 492.71 miles de toneladas en 2011. Esta oferta registró un comportamiento ascendente casi en forma lineal durante el periodo 2001-2011 (gráfica 3) con una tasa de crecimiento media anual de 3.39 por ciento.

\section{Gráfica 3}

Exportación de miel de abeja a nivel mundial

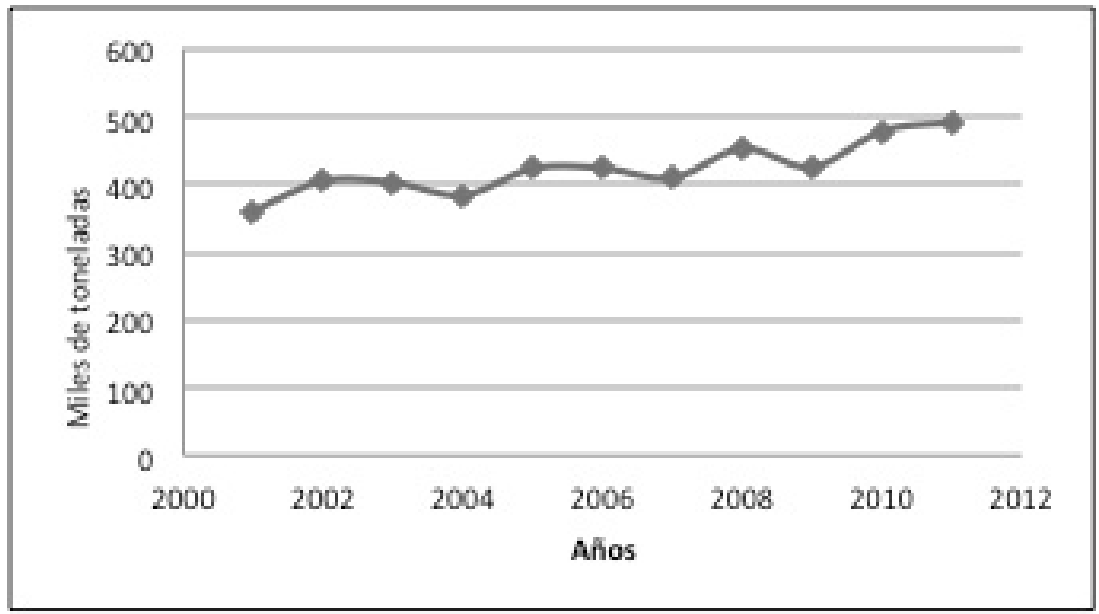

Fuente: elaboración propia con datos de FAOSTAT, 2013.

De entre los países que conforman el mayor volumen de exportaciones de miel de abeja en el mercado mundial se puede observar que China (primer productor mundial) es el país que encabeza la lista con una exportación que pasó de 107.35 a 101.46 miles de toneladas en el periodo de 2001 a 2011 (cuadro 8), su participación promedio en el total mundial representó $20.97 \%$, sin embargo, su contribución a esta oferta varió en forma significativa, ya que fue de sólo $20.59 \%$ en 2011, cuando en 2001 representaba $29.74 \%$ de dicho total. Le sigue en importancia Argentina con un volumen de exportación que también decreció en el periodo citado, de 73.03 a 72.36 miles de toneladas, su participación en el total mundial el representó 18.05 por ciento. 


\section{Cuadro 8}

Principales países exportadores de miel de abeja

(miles de toneladas)

\begin{tabular}{|c|c|c|c|c|c|c|c|c|c|c|c|}
\hline $\begin{array}{l}\text { Países/ } \\
\text { Años }\end{array}$ & 2001 & 2002 & 2003 & 2004 & 2005 & 2006 & 2007 & 2008 & 2009 & 2010 & 2011 \\
\hline China & 107.35 & 77.28 & 87.47 & 86.21 & 93.56 & 82.68 & 65.62 & 89.63 & 78.53 & 103.30 & 101.46 \\
\hline Argentina & 73.03 & 79.99 & 70.50 & 62.54 & 107.67 & 104.00 & 79.86 & 69.23 & 57.97 & 57.32 & 72.36 \\
\hline India & 3.21 & 6.65 & 6.96 & 10.35 & 16.77 & 8.14 & 12.23 & 15.59 & 13.31 & 22.65 & 28.94 \\
\hline VietNam & 7.60 & 15.88 & 10.55 & 15.56 & 16.21 & 14.65 & 16.73 & 19.81 & 18.18 & 22.54 & 28.03 \\
\hline México & 22.92 & 34.46 & 25.02 & 23.37 & 19.03 & 25.47 & 30.91 & 29.65 & 26.98 & 26.51 & 26.89 \\
\hline Brasil & 2.49 & 12.64 & 19.27 & 21.03 & 14.44 & 14.60 & 12.91 & 18.27 & 25.99 & 18.63 & 22.40 \\
\hline Alemania & 20.27 & 22.22 & 21.16 & 22.37 & 23.31 & 20.96 & 23.77 & 27.60 & 22.02 & 20.53 & 18.95 \\
\hline España & 7.97 & 14.83 & 11.63 & 9.91 & 9.60 & 11.06 & 13.88 & 16.34 & 16.27 & 21.76 & 18.77 \\
\hline Bélgica & 6.02 & 3.73 & 2.50 & 3.40 & 5.10 & 4.93 & 4.21 & 10.18 & 13.30 & 18.30 & 16.83 \\
\hline Uruguay & 9.65 & 9.47 & 9.18 & 13.36 & 8.88 & 12.08 & 14.21 & 8.98 & 6.13 & 7.95 & 15.24 \\
\hline Hungría & 12.72 & 15.02 & 15.81 & 14.96 & 18.81 & 19.44 & 23.87 & 24.18 & 14.24 & 13.90 & 12.42 \\
\hline Rumania & 6.87 & 5.79 & 9.64 & 8.76 & 6.63 & 9.61 & 6.25 & 7.09 & 10.65 & 11.02 & 9.90 \\
\hline Ucrania & 1.41 & 3.37 & 3.19 & 4.64 & 3.81 & 6.56 & 3.52 & 3.26 & 7.36 & 5.38 & 9.87 \\
\hline Canadá & 12.86 & 22.92 & 15.04 & 14.02 & 12.38 & 13.59 & 16.76 & 22.64 & 12.16 & 15.14 & 9.57 \\
\hline Tailandia & 4.36 & 4.44 & 2.52 & 2.55 & 4.33 & 3.81 & 7.70 & 3.20 & 5.86 & 6.85 & 8.77 \\
\hline Chile & 6.51 & 6.23 & 12.81 & 5.39 & 7.16 & 7.48 & 7.32 & 10.27 & 9.85 & 8.62 & 7.53 \\
\hline Bulgaria & 3.38 & 4.07 & 6.45 & 5.62 & 3.63 & 4.68 & 3.81 & 3.36 & 6.12 & 8.54 & 6.85 \\
\hline $\begin{array}{l}\text { Estados } \\
\text { Unidos }\end{array}$ & 3.41 & 3.55 & 5.03 & 4.07 & 3.91 & 3.18 & 4.00 & 5.73 & 4.77 & 11.00 & 6.44 \\
\hline Italia & 3.71 & 3.80 & 2.54 & 2.69 & 4.00 & 3.59 & 3.88 & 3.95 & 3.40 & 6.96 & 6.44 \\
\hline $\begin{array}{c}\text { Nueva } \\
\text { Zelandia }\end{array}$ & 3.41 & 2.55 & 3.19 & 2.77 & 3.63 & 4.13 & 4.87 & 5.79 & 8.21 & 7.31 & 5.47 \\
\hline Mundo & 360.95 & 405.58 & 403.39 & 384.46 & 423.90 & 424.70 & 410.08 & 45.358 & 42.614 & 47.939 & 492.71 \\
\hline
\end{tabular}

Fuente:elaboración propia con datos de FAOSTAT, 2013.

De la información recabada también se observa, un cambio en el rol que ocupaban los países con importancia en la producción y los que están integrados al comercio internacional de la miel. Por ejemplo, se observa que Estados Unidos, que ocupaba el cuarto lugar como productor de miel de abeja en el ámbito mundial, se ubica en el décimo septimo lugar como país 
exportador con un volumen promedio de exportación de apenas $0.79 \%$ del total mundial para el periodo 2001-2011. México, por su parte, se coloca como el tercer país con mayor volumen de exportación de miel de abeja, dato consistente con lo encontrado por Magaña et al. (2017), en el año 2001 fueron 22.92 mil toneladas, en tanto que para el 2011 alcanzó un total de 26.89 mil toneladas. Por consiguiente, el país presentó un incremento en sus exportaciones de miel hacia el mundo, con una tasa de crecimiento media anual de $3.96 \%$, lo que lo posicionó como uno de los países competidores importantes en el mercado mundial de este producto pecuario (exporta su miel principalmente a Alemania, Reino Unido y Estados Unidos, según datos de la FAO, 2013).

Es importante señalar que los cinco principales países exportadores de miel de abeja en el periodo, China, Argentina, México, Alemania y Brasil, concentraron en promedio 35\% del total de la oferta externa mundial. Estas cifras proporcionan una idea de la estructura y concentración del comercio internacional de la miel (de características oligopólicas de acuerdo con Parkin y Loría (2010)), ya que la diferencia de estos países con Vietnam, sexto exportador mundial, es significativa; el cual aportó, en promedio, sólo $2.74 \%$ del mercado externo. En lo particular, de los principales países que conforman el volumen de la oferta externa de miel de abeja, el volumen de Brasil fue el que presentó el comportamiento más dinámico de 2001 a 2011, al crecer en promedio 50.3 puntos porcentuales, le siguieron en importancia India (33.2\%), Vietnam (19.01\%) y México (3.96\%).

Por otra parte, cuando se analiza el valor de las exportaciones de miel, se constata que el orden que ocupa cada país en este rubro es diferente al orden e importancia alcanzada por volumen. Argentina, segundo en términos de volumen, ostenta el primer lugar en este rubro con un valor que creció de 71,508 miles de dólares en 2001 a 223,448 miles de dólares en 2011 con una tasa media anual de crecimiento de 2.75 por ciento. Lo mismo ocurre en la segunda posición en cuanto a este indicador, China, quien por volumen ocupaba el primer lugar, presentó durante el periodo estudiado una tasa media de crecimiento de 1.40\%; al pasar sus exportaciones de 95,831 miles de dólares en 2001 a 201,375 miles de dólares en el 2011. Alemania y México son los países que detentan el tercer y cuarto lugar; al desplazar a India y Vietnam, 
quienes ocupaban estos lugares de acuerdo con el volumen de exportación. Alemania se caracterizó por presentar movimientos en el valor de sus exportaciones durante el periodo y que registra su clímax en el año 2008 cuando alcanza los 121,409 miles de dólares y finaliza el 2011 con la cantidad que registró en 2001 (34,737 miles de dólares); aunque con una tasa media anual de crecimiento negativa de $-0.05 \%$. En tanto que México pasó de un valor de 28,086 miles de dólares en 2001 a 90,359 miles de dólares en el 2011 por este concepto y con una tasa media anual de crecimiento de 3.95 por ciento.

\section{TENDENCIAS DEL CONSUMO}

La tendencia del saldo de la balanza comercial mundial de miel de abeja presentó en general una condición deficitaria en su comportamiento durante el periodo 2001 - 2011 (gráfica 4) con una tendencia errática, lo cual evidencia que el destino anual de la producción o demanda interna y exportación, resultó menor a su disponibilidad u oferta interna e importación ${ }^{1}$ (Parkin y Loría, 2010).

\section{Gráfica 4}

Saldo mundial de la balanza comercial de la miel de abeja

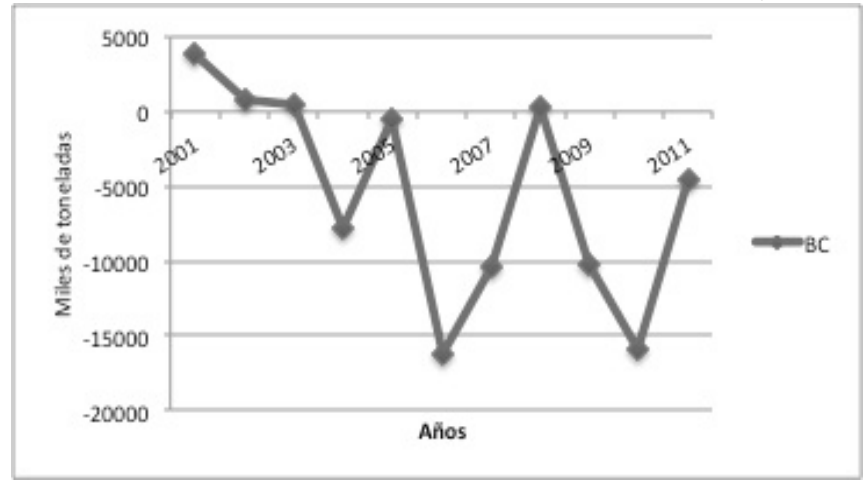

Fuente: elaboración propia con datos de FAOSTAT, 2013.

1 Recuérdese la identidad macroeconómica que relaciona la producción (oferta) global con la demanda global en cualquier economía y que da lugar al equilibrio del mercado en donde la resultante sintetizada es: PIB+Importaciones $=$ Demanda interna+Exportaciones. Esta identidad indica en materia de comercio exterior que cuando las exportaciones resultan inferiores a las importaciones significa que se ha comercializado menos de lo comprado en el exterior y que se producirá una diferencia negativa en la balanza comercial. 
Se puede observar que del año 2001 al 2003 la citada balanza registró niveles de superávit, el más alto en 2001. En tanto que en los años 2006 y 2010 el saldo de la misma registró sus déficits más altos. La condición de déficit de la balanza comercial, determinada por la dinámica de la producción mundial de la miel de abeja, es producto del incremento de los inventarios de este producto en el mundo, lo cual da lugar a que la tasa de crecimiento promedio anual de las importaciones supere a la del consumo. Es decir, que la producción de miel es más dinámica que su consumo en algunos países, aunque de manera agregada en el mediano plazo ambas variables tienden a igualarse (Parkin y Loría, 2010).

Por otra parte, en el periodo 2001-2011 el consumo mundial de miel de abeja fue en promedio de 1,441.18 miles de toneladas anuales, pasó de 1,269.36 miles de toneladas en 2001 a 1,577.32 miles de toneladas en 2011, esto es, una diferencia de 307.96 miles de toneladas en total (cuadro 9). Asímismo, se caracterizó por registrar un crecimiento promedio anual significativo de $2.23 \%$, aunque con tasas variables y con una tendencia decreciente a partir del año 2006.

\section{Cuadro 9}

Consumo aparente mundial de miel de abeja (miles de toneladas)

\begin{tabular}{|c|c|}
\hline Años & Consumo mundial \\
\hline 2001 & $1,269.36$ \\
\hline 2002 & $1,288.75$ \\
\hline 2003 & $1,327.10$ \\
\hline 2004 & $1,372.75$ \\
\hline 2005 & $1,418.11$ \\
\hline 2006 & $1,521.30$ \\
\hline 2007 & $1,472.17$ \\
\hline 2008 & $1,520.54$ \\
\hline 2009 & $1,520.38$ \\
\hline 2010 & $1,562.90$ \\
\hline 2011 & $1,577.32$ \\
\hline
\end{tabular}

Fuente: elaboración propia con datos de FAOSTAT, 2013. 
El consumo aparente de miel de abeja por país seleccionado, según su condición de exportador, importador o de ambas, se presenta en el cuadro 10, en el se observa que China, el principal productor, también ocupa el primer lugar en este rubro, registra en el año 2011 un consumo aparente de 352.36 miles de toneladas. Los otros países que figuran en ese mismo año en el ámbito mundial por su nivel de consumo, después de China, son en orden descendente, Estados Unidos, Turquía, Alemania, Rusia, Ucrania, Etiopía, Irán, Japón y Reino Unido.

\section{Cuadro 10}

Consumo Aparente de miel de abeja por país seleccionado (miles de toneladas)

\begin{tabular}{|c|c|c|c|c|c|c|c|c|c|c|c|}
\hline Países/Años & 2001 & 2002 & 2003 & 2004 & 2005 & 2006 & 2007 & 2008 & 2009 & 2010 & 2011 \\
\hline China & 150.88 & 195.40 & 213.43 & 219.83 & 212.56 & 260.22 & 298.05 & 324.08 & 337.84 & 313.39 & 352.36 \\
\hline $\begin{array}{l}\text { Estados } \\
\text { Unidos }\end{array}$ & 146.67 & 166.35 & 169.55 & 160.23 & 174.56 & 193.13 & 168.73 & 173.53 & 157.12 & 183.17 & 191.35 \\
\hline Turquía & 56.19 & 59.66 & 55.23 & 68.42 & 80.34 & 81.97 & 73.59 & 82.21 & 81.11 & 79.85 & 93.14 \\
\hline Alemania & 97.88 & 91.31 & 96.06 & 92.16 & 93.37 & 91.74 & 88.57 & 80.05 & 77.01 & 92.16 & 84.25 \\
\hline $\begin{array}{l}\text { Federación } \\
\text { de Rusia }\end{array}$ & 52.73 & 49.80 & 50.02 & 53.28 & 52.28 & 55.85 & 54.02 & 58.38 & 55.76 & 56.80 & 65.32 \\
\hline Ucrania & 58.69 & 47.83 & 50.48 & 53.24 & 67.71 & 69.07 & 64.19 & 71.76 & 66.77 & 65.62 & 60.43 \\
\hline Etiopía & 33.78 & 39.60 & 37.80 & 40.89 & 36.00 & 51.21 & 41.79 & 41.83 & 39.39 & 40.91 & 52.95 \\
\hline Irán & 24.58 & 26.36 & 13.16 & 27.34 & 33.71 & 34.40 & 45.36 & 38.43 & 45.84 & 44.76 & 45.38 \\
\hline Japón & 43.45 & 48.18 & 47.13 & 50.60 & 46.32 & 43.11 & 40.94 & 44.97 & 39.53 & 42.56 & 43.01 \\
\hline Reino Unido & 28.60 & 32.73 & 27.91 & 29.45 & 31.70 & 35.02 & 36.07 & 36.29 & 36.71 & 35.73 & 39.31 \\
\hline Francia & 27.93 & 29.92 & 27.80 & 30.68 & 32.19 & 31.50 & 34.87 & 37.12 & 35.24 & 35.27 & 36.87 \\
\hline España & 38.40 & 31.80 & 34.76 & 38.06 & 32.64 & 37.38 & 29.52 & 30.31 & 31.33 & 30.51 & 36.51 \\
\hline $\begin{array}{l}\text { República } \\
\text { Unida de } \\
\text { Tanzanía }\end{array}$ & 26.51 & 31.88 & 26.09 & 25.48 & 34.31 & 31.63 & 32.99 & 34.91 & 32.95 & 33.69 & 33.59 \\
\hline India & 49.89 & 48.74 & 45.19 & 44.25 & 35.73 & 44.87 & 41.30 & 42.21 & 42.79 & 39.76 & 31.92 \\
\hline México & 37.49 & 25.22 & 32.04 & 33.55 & 31.61 & 30.50 & 24.55 & 25.63 & 29.09 & 29.29 & 30.90 \\
\hline Canadá & 27.74 & 22.29 & 28.39 & 29.11 & 31.94 & 39.71 & 19.04 & 10.44 & 24.65 & 21.82 & 28.79 \\
\hline $\begin{array}{c}\text { República de } \\
\text { Corea }\end{array}$ & 22.45 & 20.43 & 18.65 & 16.77 & 24.98 & 23.71 & 27.00 & 26.62 & 28.53 & 24.54 & 24.65 \\
\hline Kenya & 23.46 & 22.05 & 19.97 & 21.57 & 22.08 & 25.05 & 25.21 & 27.25 & 25.12 & 24.06 & 24.06 \\
\hline Angola & 24.00 & 25.33 & 23.04 & 21.59 & 24.02 & 23.05 & 25.61 & 26.63 & 25.62 & 22.96 & 22.98 \\
\hline Polonia & 12.55 & 14.14 & 15.68 & 15.18 & 14.64 & 18.28 & 17.80 & 18.00 & 19.94 & 20.57 & 22.76 \\
\hline
\end{tabular}

Fuente: elaboración propia con datos de FAOSTAT, 2013. 
Se puede inferir también del cuadro anterior que los mayores niveles de consumo de miel de abeja se registran en las naciones productoras, como China y Tuquía, así como en Alemania, Japón y en Estados Unidos, los tres últimos ubicados entre los mayores países importadores de este producto en la actualidad. Lo cual es un claro indicador de que el nivel de consumo de la miel en el mundo es amplio y creciente y que, por tanto, existe un mercado de oportunidad que no está siendo atendido en su totalidad, que debe de ser aprovechado por países productores como México.

México se ubica en el año 2011 en el lugar décimo quinto con un consumo aparente de 30.90 miles de toneladas y, en general, el consumo mexicano de miel de abeja ha seguido una tendencia hacia la baja (gráfica 5). Sin embargo, como se observa también en la gráfica, a partir del año 2006 y hasta el 2011 se ha ampliado la brecha entre la producción y el consumo interno de miel en el país, debido principalmente a la capacidad y oportunidad de exportación que se tiene de este producto natural. Por lo que dicha diferencia, que equivale a sus ventas al exterior, es la que está determinando el comportamiento de su consumo de miel, el cual esta siguiendo la pauta que le impone la producción de acuerdo con los principios económicos propuestos al respecto por Parkin y Loría (2010).

\section{Gráfica 5}

Producción y consumo aparente de miel de abeja en México

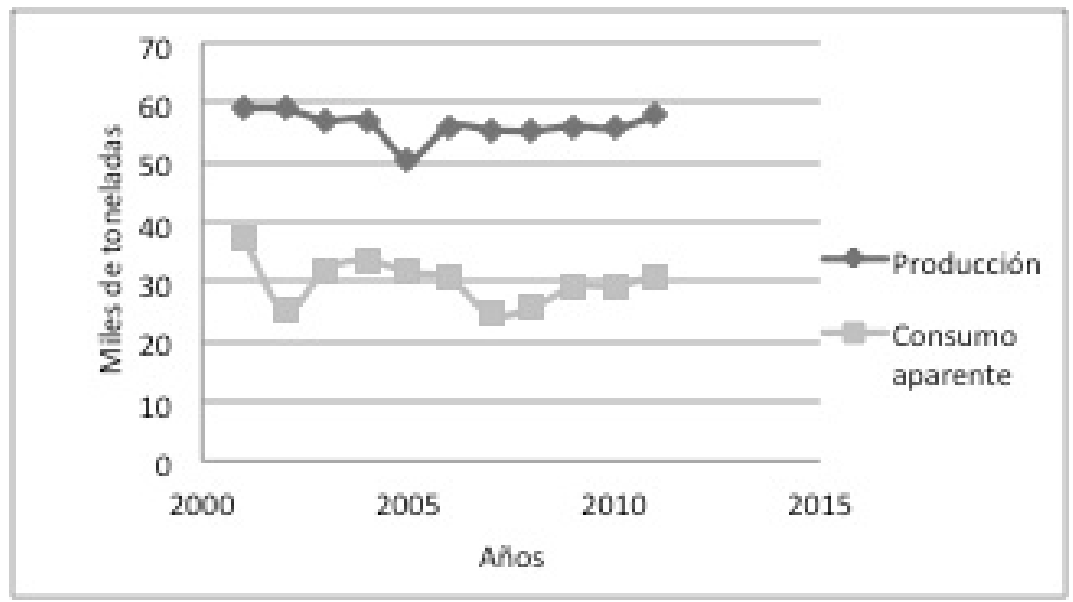

Fuente: elaboración propia con datos de FAOSTAT, 2013.

Revista de Economía - Vol. XXXV - Núm. 90 


\section{PAÍSES IMPORTADORES}

La demanda de importación de miel en el mercado mundial siguió, en general, un comportamiento ascendente durante el periodo de 2001 a 2011, como se observa en la gráfica 6, pasó de un monto de 357.04 miles de toneladas en 2001 a 497.20 miles de toneladas en el año 2011, con una tasa de crecimiento media anual de 3.57 por ciento.

\section{Gráfica 6}

Importación de miel de abeja a nivel mundial

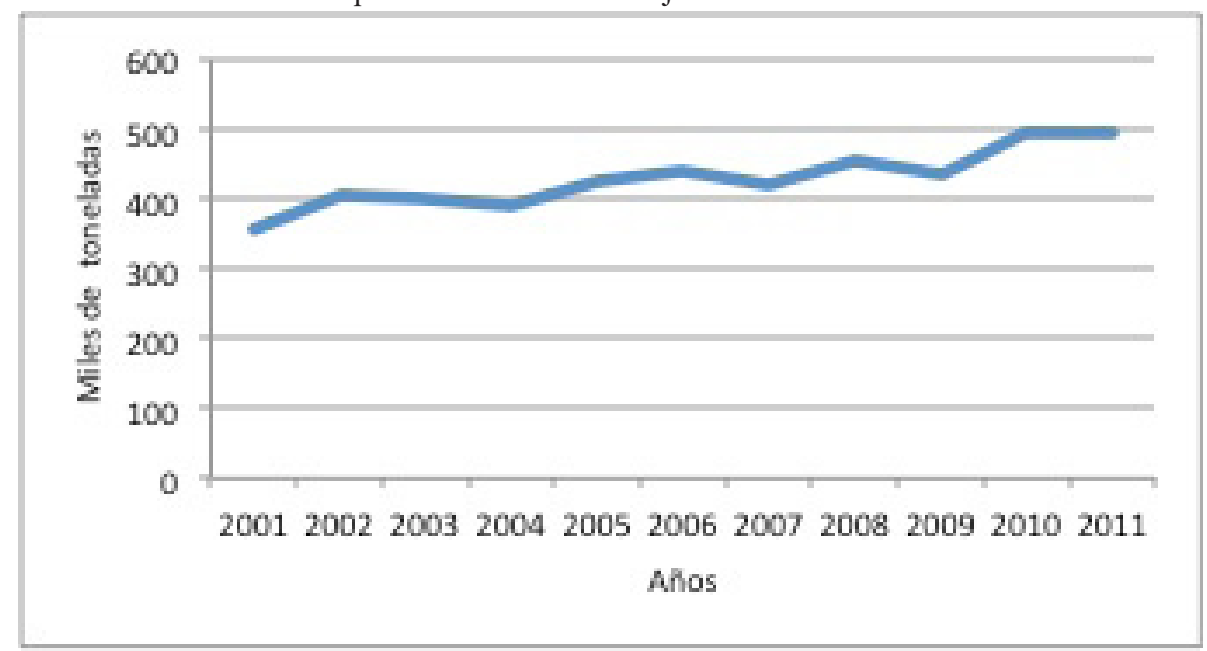

Fuente:elaboración propia con datos de FAOSTAT, 2013.

Los principales países importadores de miel de abeja en el ámbito mundial, como se aprecia en la lista del cuadro 11, son países desarrollados. Encabeza el grupo Estados Unidos con un volumen promedio anual de 98.25 mil toneladas durante el periodo 2001-2011, con una tasa media de crecimiento anual de $8.58 \%$ y representando del total mundial 26.25 por ciento. En importancia le sigue Alemania con 91.47 mil toneladas de miel, una tasa de $-1.42 \%$ y una participación porcentual de $15.56 \%$; despues Japón con importaciones de 41.57 mil toneladas, una tasa de $0.42 \%$ y una participación porcentual de $8.16 \%$; el Reino Unido con 28.33 mil toneladas, una tasa de $3.91 \%$ y una participación de $7.17 \%$ y, por último, 
Francia con una importación de 20.62 mil toneladas, una tasa media anual de $6.29 \%$ y una participación de 5.46 por ciento. Así, estos cinco países concentran $66.28 \%$ del total de la importación mundial de miel manifestando con esto una estructura de mercado oligopsónica (Parkin y Loría, 2010).

\section{Cuadro 11}

Principales países importadores de miel de abeja

(miles de toneladas)

\begin{tabular}{|c|c|c|c|c|c|c|c|c|c|c|c|}
\hline Países & 2001 & 2002 & 2003 & 2004 & 2005 & 2006 & 2007 & 2008 & 2009 & 2010 & 2011 \\
\hline $\begin{array}{c}\text { E s t a d o s } \\
\text { Unidos }\end{array}$ & 65.75 & 92.01 & 92.15 & 81.03 & 105.54 & 126.07 & 105.44 & 104.96 & 95.47 & 114.13 & 130.49 \\
\hline Alemania & 92.20 & 98.91 & 93.53 & 88.96 & 95.45 & 87.50 & 94.08 & 91.92 & 82.57 & 89.55 & 77.36 \\
\hline Japón & 40.19 & 45.04 & 43.78 & 47.03 & 43.16 & 40.07 & 37.89 & 41.68 & 36.92 & 39.95 & 40.58 \\
\hline Reino Unido & 26.15 & 29.90 & 21.87 & 25.89 & 27.98 & 29.18 & 30.11 & 30.30 & 30.41 & 31.51 & 35.64 \\
\hline Francia & 15.55 & 16.84 & 15.16 & 17.08 & 19.26 & 22.11 & 23.49 & 27.96 & 23.41 & 25.39 & 27.15 \\
\hline Bélgica & 10.47 & 8.56 & 6.65 & 6.86 & 8.25 & 9.76 & 8.58 & 16.34 & 18.58 & 22.10 & 21.05 \\
\hline España & 14.76 & 10.91 & 11.12 & 13.76 & 15.02 & 17.78 & 11.56 & 16.29 & 15.26 & 17.71 & 20.65 \\
\hline Italia & 11.96 & 14.07 & 14.45 & 15.39 & 1.403 & 13.85 & 10.69 & 13.39 & 15.17 & 14.55 & 15.15 \\
\hline $\begin{array}{l}\text { Arabia } \\
\text { Saudita }\end{array}$ & 7.73 & 4.92 & 8.99 & 11.36 & 11.26 & 13.36 & 9139 & 8.82 & 8.22 & 12.81 & 14.01 \\
\hline Polonia & 3.18 & 4.55 & 4.49 & 4.09 & 4.95 & 5.09 & 3.37 & 4.48 & 7.44 & 9.18 & 13.61 \\
\hline Países Bajos & 4.55 & 5.49 & 9.57 & 7.28 & 11.52 & 10.32 & 8.44 & 8.58 & 10.58 & 10.09 & 11.96 \\
\hline China & 3.87 & 4.85 & 6.17 & 8.05 & 6.60 & 5.32 & 6.45 & 6.49 & 9.00 & 7.54 & 7.74 \\
\hline Suiza & 6.92 & 6.75 & 6.79 & 6.13 & 6.29 & 6.41 & 7.04 & 7.24 & 7.55 & 7.89 & 7.43 \\
\hline Austria & 4.61 & 5.47 & 4.30 & 4.49 & 5.02 & 5.28 & 5.12 & 5.47 & 6.18 & 6.94 & 6.06 \\
\hline $\begin{array}{c}\text { Federación } \\
\text { de Rusia }\end{array}$ & 0.31 & 0.51 & 2.32 & 0.89 & 0.47 & 0.38 & 0.50 & 1.07 & 2.36 & 5.37 & 5.40 \\
\hline Dinamarca & 6.56 & 4.41 & 5.49 & 4.66 & 5.57 & 4.97 & 4.33 & 4.80 & 4.12 & 4.37 & 5.19 \\
\hline Tailandia & 3.12 & 3.33 & 0.28 & 0.70 & 0.34 & 0.82 & 0.56 & 0.25 & 0.60 & 2.97 & 5.07 \\
\hline Suecia & 2.43 & 2.65 & 2.62 & 2.55 & 2.57 & 2,53 & 2.73 & 2.80 & 3.60 & 3.97 & 4.06 \\
\hline Malasia & 1.96 & 2.49 & 4.90 & 2.52 & 2.19 & 2.48 & 4.93 & 6.75 & 8.23 & 7.91 & 3.16 \\
\hline Australia & 0.77 & 4.49 & 8.78 & 2.58 & 1.21 & 0.74 & 1.54 & 5.24 & 4.74 & 3.32 & 3.07 \\
\hline Mundo & 357.04 & 404.87 & 402.86 & 392.27 & 424.37 & 440.90 & 420.55 & 453.35 & 436.40 & 495.28 & 497.20 \\
\hline
\end{tabular}

Fuente: Elaboración propia con datos de FAOSTAT, 2013. 
Con respecto a la importancia que simboliza el valor de la importación de miel por país, en el ámbito mundial (la demanda externa), se observó que se deriva de ésta un comportamiento parecido al expresado en cuanto a volumen. El país que tiene la mayor participación en el valor promedio anual de las importaciones durante el periodo 2001 - 2011 fue nuevamente Estados Unidos, registró un total de 401,186 miles de dólares en 2011 lo que representó a nivel mundial $23.72 \%$ de dicho total; en segundo lugar de importancia se encuentra Alemania con un registro de 270,833 miles de dólares, es decir, $16.01 \%$, y en tercero se encuentra el Reino Unido con 126,380 miles de dólares que equivalen a nivel mundial en términos porcentuales 7.47 del total importado.

\section{COMPETITIVIDAD EN EL MERCADO INTERNACIONAL DE LA MIEL}

Como se observa en el cuadro 12, de los veinte principales países productores de miel de abeja en el mundo, Argentina ocupa, de acuerdo con el indicador de transabilidad, el primer lugar en competitividad en el periodo 2001-2011, ya que tiene la capacidad de enviar al mercado internacional (apertura exportadora) una cantidad de miel equivalente a 17.50 veces su consumo interno y de necesitar del exterior (penetración de importaciones) una proporción de sólo 0.02 (valores similares a los encontrados por Magaña et al., 2017), ${ }^{2}$ la diferencia entre ambos expresado en porcentaje es de $1,747.81 \%$ y representa el exceso de oferta en su mercado interno. El segundo lugar lo ocupa Hungría con un indicador de transabilidad de $601.69 \%$, el tercero le corresponde a Chile (580.85\%), en tanto que el cuarto y quinto lugar lo ocupan Uruguay y Cuba con indicadores de 498.09 y 462.32 por ciento, respectivamente.

2 Las diferencias en los valores son resultado de la base de cálculo en que se basan los trabajos, el de los autores de este documento es de once años mientras que la del artículo de Magaña et al. es de doce. 


\section{Cuadro 12}

Indicador de transabilidad de los principales países productores de miel de abeja

\begin{tabular}{|c|c|c|c|c|c|}
\hline $\begin{array}{l}\text { Posición } \\
\text { competitiva }\end{array}$ & Países & Característica & $\begin{array}{l}\text { Grado de apertu- } \\
\text { ra exportadora }\end{array}$ & $\begin{array}{l}\text { Grado de penetración } \\
\text { de importaciones }\end{array}$ & $\begin{array}{l}\text { Indicador de } \\
\text { transabilidad }\end{array}$ \\
\hline 14 & China & exceso de oferta & 33.81 & 2.5 & 31.31 \\
\hline 1 & Argentina & exceso de oferta & 1750.18 & 2.37 & 1747.81 \\
\hline 22 & Turquía & exceso de oferta & 5.94 & 0.35 & 5.59 \\
\hline 45 & Estados Unidos & exceso de demanda & 2.92 & 59.07 & -56.14 \\
\hline 19 & Ucrania & exceso de oferta & 8.11 & 0.09 & 8.02 \\
\hline 9 & México & exceso de oferta & 88.28 & 0.7 & 87.58 \\
\hline 16 & India & exceso de oferta & 31.03 & 3.95 & 27.08 \\
\hline 33 & $\begin{array}{l}\text { Federación de } \\
\text { Rusia }\end{array}$ & exceso de demanda & 0.35 & 3.24 & -2.89 \\
\hline 25 & Etiopía & exceso de oferta & 0.5 & 0.02 & 0.49 \\
\hline 23 & Irán & exceso de oferta & 4.74 & 0.02 & 4.72 \\
\hline 13 & Canadá & exceso de oferta & 58.85 & 22.25 & 36.6 \\
\hline 8 & Brasil & exceso de oferta & 97.51 & 0.21 & 97.29 \\
\hline 35 & España & exceso de demanda & 40.95 & 44.4 & -3.45 \\
\hline 24 & $\begin{array}{l}\text { República Uni- } \\
\text { da de Tanzanía }\end{array}$ & exceso de oferta & 1.59 & 0.06 & 1.53 \\
\hline 29 & Angola & exceso de demanda & 0 & 0.17 & -0.17 \\
\hline 34 & $\begin{array}{l}\text { República de } \\
\text { Corea }\end{array}$ & exceso de demanda & 0.02 & 2.91 & -2.89 \\
\hline 47 & Alemania & exceso de demanda & 24.7 & 100.75 & -76.06 \\
\hline 2 & Hungría & exceso de oferta & 640.9 & 39.2 & 601.69 \\
\hline
\end{tabular}

Fuente: Estimación propia con base en datos 2001-2011 de FAOSTAT.

Alemania, Estados Unidos y España que figuran entre los quince principales países productores a nivel mundial presentaron un indicador de transabilidad negativo de $-76.06 \%,-56.14 \%$ y $-3.45 \%$, respectivamente, esto es, su excedente de demanda o déficit de consumo en su mercado interno. De esta manera, los tres países que requieren satisfacer ese déficit en su demanda interna con producto del exterior representan una 
importante alternativa de venta para México que produce y exporta este producto en el mercado internacional con ventaja (como se indicó antes, los dos primeros de estos países es hacia donde se exporta la mayoría de la miel mexicana, ademas de ser los principales importadores de dicho producto en el mundo).

México en este contexto demuestra una competitividad que le pondera en el noveno lugar debido a que su indicador de transabilidad es de $87.58 \%$, su exceso de oferta o superávit de producción en su mercado interno, circunstancia que no coincide con lo reportado en el estudio de Magaña y colaboradores en 2017. El signo positivo del indicador demuestra que requiere del exterior una menor cantidad de miel que la que envía a otros países lo que verifica que es un país competitivo (situación respaldada por el bajo grado de penetración de sus importaciones, atribuible al valor que se presenta con respecto a este índice en el cuadro 12, sin embargo, estos valores relativos hacen ver que más que poseer una capacidad exportadora de miel, lo que México tiene es, por una parte, los recursos naturales (flora nectarpolinifera) para producir este bien primario (Villegas et al., 2000) y por otra, la disponibilidad de excedentes originados por la baja demanda interna de sus habitantes (Güemes, Echazarreta y Villanueva, 2002; Soto, Chiatchoua y Castañeda, 2015) por la miel (producto del bajo nivel de su ingreso percápita y por la limitada preferencia por este endulzante natural). No obstante lo anterior, es de importancia señalar que superó su calificación bajo este indicador al pasar del lugar número 21 en el periodo 2002-2006 (Antequera y Guido, 2007) al número nueve en el de 2001-2011, un avance de doce lugares, y mejorar así su participación en el mercado mundial de la miel.

Por otro lado, de acuerdo con el indicador de balanza comercial relativa, del año 2001 al 2011 el país que se posiciona en el primer lugar es República Dominicana al tener la mayor ventaja en el mercado internacional de la miel con un índice de $100 \%$ a su favor, le siguen en orden descendente Chile y Uruguay con $99.97 \%$ cada uno, Cuba con $99.89 \%$ y en quinto y sexto lugar Argentina y Brasil con un índice de $99.73 \%$ y 99.56\%, respectivamente (cuadro 13 ). 


\section{Cuadro 13}

Indicador de balanza comercial relativa de los principales países productores de miel de abeja

\begin{tabular}{|c|c|c|c|c|}
\hline Posición competitiva & Países & $\begin{array}{l}\text { Indicador de balanza } \\
\text { comercial relativa }\end{array}$ & Característica & $\begin{array}{l}\text { Saldo neto balanza } \\
\text { comercial (tons.) }\end{array}$ \\
\hline 19 & China & 86.21 & ventaja & 901,003 \\
\hline 5 & Argentina & 99.73 & ventaja & 833,322 \\
\hline 17 & Turquía & 88.76 & ventaja & 45,337 \\
\hline 43 & Estados Unidos & -90.57 & desventaja & $-1057,963$ \\
\hline 10 & Ucrania & 97.74 & ventaja & 51,791 \\
\hline 9 & México & 98.44 & ventaja & 288,918 \\
\hline 20 & India & 77.39 & ventaja & 126,347 \\
\hline 38 & Federación de Rusia & -80.27 & desventaja & $-17,440$ \\
\hline 12 & Etiopía & 93.66 & ventaja & 2,218 \\
\hline 7 & Irán & 99.28 & ventaja & 17,924 \\
\hline 24 & Canadá & 45.13 & ventaja & 103,915 \\
\hline 6 & Brasil & 99.56 & ventaja & 182,267 \\
\hline 28 & España & -4.037 & desventaja & $-12,793$ \\
\hline 14 & $\begin{array}{c}\text { República Unida de } \\
\text { Tanzanía }\end{array}$ & 92.279 & ventaja & 4,542 \\
\hline 49 & Angola & -100 & desventaja & -449 \\
\hline 46 & República de Corea & -98.59 & desventaja & $-7,400$ \\
\hline 34 & Alemania & -60.63 & desventaja & $-748,866$ \\
\hline 18 & Hungría & 88.47 & ventaja & 174,039 \\
\hline
\end{tabular}

Fuente: Estimación propia con base en datos 2001-2011 de FAOSTAT.

Paises productores importantes como España, la Federación Rusa y Estados Unidos, al registrar un saldo negativo en su balanza comercial durante el periodo considerado y presentar un indicador de balanza comercial relativa de $-4.04 \%,-80.27 \%$ y $-90.57 \%$ respectivamente, demuestran una condición clara de desventaja en el mercado del endulzante en cuestión. Es importante mencionar que en ello influye mucho la capacidad que tienen estos países de asignar mayores recursos, como el capital, para incrementar su producción y así reducir su déficit comercial 
(Parkin y Loría, 2010); pero según la disponibilidad de estos recursos o de la valoración de los costos de oportunidad que hagan de ellos, de su uso en otras actividades (ventaja comparativa), es que decidirán si los asignan a la producción de miel o si continuan dependiendo del mercado internacional para satisfacer su demanda interna (Macías, 2010), hecho que se constata en la estructura de las exportaciones de mercancías por país productor de miel, como es el caso de Estados Unidos.

El país productor que en mayor medida ha incrementado su déficit comercial de 2001 a 2011 es Rusia su saldo negativo pasó de -0.07 mil toneladas de miel de abeja en 2001 a -5.31 mil en 2011; un incremento de 7,385.91\% en once años. Estados Unidos es el segundo de los cuatro, su saldo negativo de -62.34 miles de toneladas de miel en 2001 pasó a -124.05 miles en 2011; un incremento de $198.88 \%$. Sin embargo, a diferencia de los dos países anteriores, España si redujo su déficit comercial ya que el saldo negativo de su balanza comercial pasó de -6.79 mil toneladas a -1.88 mil toneladas, un decremento de $72.24 \%$ durante el citado periodo.

En cuanto a la posición competitiva de México en el mundo con base en este índice, mantiene la misma posición que con el indicador de transabilidad, esto es, la novena, lo que demuestra una ventaja competitiva de $98.44 \%$ y una mejora en su posición, respecto a lo reportado por Antequera y Guido (2007) para el periodo 2002-2006 (lugar 21), aunque con una ligera reducción en su valor porcentual. Es decir, que en el sector agropecuario mexicano la producción de miel de abeja es un producto cuya oferta rebasa su demanda interna, lo cual es consistente con lo señalado al respecto por Magaña et al. (2012) y, por lo tanto, se cuenta con la capacidad para exportar a este mercado mundial (Kruggman, 2004; Soto, Chiatchoua y Castañeda, 2015). Sin embargo, México es superado al respecto, como ya se indicó antes, por varios países de América, quienes de acuerdo con dicho indicador presentaron en el periodo una mejor ventaja competitiva en este mercado.

Por último, con base en la información que se presenta en el cuadro 14 se evidencia que China es el país que posee la más alta especialización y competitividad en el mercado mundial de la miel de abeja durante el 
periodo analizado, con un valor porcentual de $19.30 \%$ y participación de $20.86 \%$ en la exportación mundial; le sigue en importancia Argentina con un índice de especialización de $17.86 \%$ y con una cobertura en el mercado de la miel de $17.89 \%$ del total de exportaciones, valoraciones que resultaron muy similares a las reportadas en el estudio de 2017 de Magaña et al.

\section{Cuadro 14}

Indicador de especialización de los principales países productores de miel de abeja

\begin{tabular}{|c|c|c|c|c|}
\hline Posición competitiva & Países & $\begin{array}{c}\text { Grado de especiali- } \\
\text { zación }\end{array}$ & Característica & $\begin{array}{c}\text { Participación en las } \\
\text { exportaciones del } \\
\text { mundo }\end{array}$ \\
\hline 1 & China & 19.31 & alto & 20.86 \\
\hline 2 & Argentina & 17.86 & alto & 17.89 \\
\hline 16 & Turquía & 0.97 & bajo & 1.03 \\
\hline 50 & Estados Unidos & -22.68 & bajo & 1.18 \\
\hline 14 & Ucrania & 1.11 & bajo & 1.12 \\
\hline 3 & México & 6.19 & intermedio & 6.24 \\
\hline 7 & India & 2.71 & bajo & 3.1 \\
\hline 39 & Federación de Rusia & -0.37 & bajo & 0.05 \\
\hline 26 & Etiopía & 0.047 & bajo & 0.05 \\
\hline 19 & Irán & 0.38 & bajo & 0.39 \\
\hline 9 & Canadá & 2.23 & bajo & 3.58 \\
\hline 4 & Brasil & 3.91 & bajo & 3.92 \\
\hline 37 & España & -0.27 & bajo & 3.26 \\
\hline 23 & $\begin{array}{c}\text { República Unida de } \\
\text { Tanzanía }\end{array}$ & 0.10 & bajo & 0.1 \\
\hline 31 & Angola & -0.01 & bajo & 0 \\
\hline 36 & República de Corea & -0.16 & bajo & 0.001 \\
\hline 49 & Alemania & -16.05 & bajo & 5.21 \\
\hline 6 & Hungría & 3.73 & bajo & 3.97 \\
\hline
\end{tabular}

Fuente: Estimación propia con datos de 2001-2011, FAOSTAT.

México aparece como el tercer país en importancia con un grado de especialización de $6.19 \%$ (cobertura en la exportación total de $6.24 \%$ ), es de característica intermedia (situación que coincide con lo encontrado por Magaña et al., 2017) y registra un importante crecimiento de acuerdo con 
este índice, ya que en el periodo 2002-2006 contaba con un nivel de sólo $2.88 \%$, aunque con la misma posición competitiva (Antequera y Guido, 2007). Esto último significa que la miel de abeja de México, al tener un grado de especializacion importante, positivo y en aumento, cuenta con ventajas relevantes para poder ampliar su nivel de exportación en el mundo.

Otros países que presentaron un indicador de especialización por arriba del uno por ciento, fueron: Vietnam $3.82 \%$, Uruguay $2.47 \%$, Chile $1.91 \%$, Bulgaria $1.16 \%$, Cuba $1.13 \%$ y Nueva Zelanda $1.09 \%$. En contraste, los países de importancia en producción que no presentan algún grado de especialización fueron Estados Unidos (-22.68\%), Alemania (-16.05\%), la Federación de Rusia (-0.37\%), España (-0.27\%) y República de Corea $(-0.16 \%)$, es decir, que este conjunto de países no presenta ventaja competitiva ni vocación exportadora en el mercado de la miel.

Con base en todo lo antes expuesto, se puede decir que México presentó un mejor nivel de ventaja competitiva y una manifiesta vocación exportadora en el mercado mundial de la miel de abeja durante el periodo 2001-2011, aunque el número de países productores que pueden participar con ventaja es cada vez mayor, el caso de Brasil, Canada, India y Ucrania. Sin embargo, este nivel de competitividad podría ser mayor si se incrementara la productividad por colmena (Lema y Delgado, 2000; Magaña et al., 2017) en las regiones productoras del país (en México esta variable creció a una tasa media anual de $1.7 \%$ de 1995 a 2011, lo cual resulta bajo si se compara con China, donde fue de $4.5 \%$ ) y si se aplicaran métodos que reduzcan los costos de producción en la actividad para generar mayores rendimientos, como la diferenciación del producto apícola nacional (normalización técnica de la miel) y el uso de nuevas tecnologías en el manejo y envasado de este producto para asegurar su rastreabilidad (Soto, Elizarrarás y Soto, 2017), dado que la base real de la integración y permanencia en el mercado mundial comprende, entre otros aspectos, un costo medio de producción relativamente menor (Parkin y Loría, 2010; Porter, 2008).

\section{CONCLUSIONES}


La apicultura en el contexto mundial ha tenido una dinámica importante al mostrar una tendencia creciente en el volumen de la producción de miel de abeja durante el periodo de 2001 a 2011, igual que en su nivel de consumo, destaca por su mayor aportación a la producción China como país. En el comercio internacional, la oferta de exportación de la miel también ha seguido un comportamiento ascendente en el citado periodo, ocurre lo mismo en lo que concierne a la demanda de importación de este producto. Sin embargo, la demanda de importación de miel superó con amplio margen a la oferta exportable, por lo que la balanza comercial mundial presentó una condición deficitaria en el periodo, en general, esto implica que se dio una perdida de competitividad en el mercado de la miel ya que dependió en mayor medida del comercio internacional para satisfacer su demanda. En cuanto a la competitividad internacional en el mercado mundial de la miel de 2001 a 2011, Argentina ocupa el primer lugar en términos del índice de transabilidad; el de balanza comercial relativa posiciona a la República Dominicana como el primer lugar, al tener la mayor ventaja en este mercado internacional; en tanto que el índice de especialización evidenció que China es el país que presentó la más alta especialización y nivel de competitividad en el mercado mundial de la miel de abeja en el periodo analizado.

En cuanto a México, el ritmo de crecimiento que presentó la producción de miel de abeja se caracterizó por un comportamiento ascendente en el periodo estudiado; sin embargo, en términos generales su tasa media anual de crecimiento, de $1.53 \%$, resultó estar por debajo de la media mundial que fue de $2.06 \%$. En su comercio internacional, el comportamiento del volumen de las exportaciones mexicanas de miel de abeja fue ascendente, pero su demanda de importaciones fue en lo general decreciente (-850.68\% en el periodo); por consiguiente su balanza comercial se caracterizó por ser superavitaria. En tanto que, de acuerdo con los indicadores de competitividad internacional, México se pondera en el lugar número nueve con respecto a los de transabilidad y de balanza comercial, lo que mejora en 12 lugares su posición en estos índices con repecto al periodo 2002-2006, además de que muestra un grado de especialidad que lo mantiene con el tercer puesto en el mercado, lo que demuestra con ésto que 
todavía posee una importante ventaja competitiva y una competitividad macroeconómica alta a nivel mundial y regional.

Por consiguente, se puede afirmar que la tendencia favorable observada en el mercado mundial de la miel de abeja se ha visto reflejada de manera importante en México de 2001 a 2011, ya que se incrementó tanto el volumen de su producción como el volumen y valor de las exportaciones nacionales del producto, lo que se evidencia en la mejor y más alta competitividad de la miel mexicana en el mercado en cuestión, sólo superada por China y Argentina en los indicadores de transabilidad y de especialización internacional. Además, de que este nivel de competitividad es posible incrementarlo en el futuro próximo si se logra una mayor productividad por colmena y se aplican métodos que reduzcan los costos de producción en la actividad para generar mayores rendimientos en los apiarios del país, con lo que se alcanzaría una mayor presencia en el mercado mundial de la miel.

\section{BIBLIOGRAFÍA}

Antequera, S. 2015. Acceso y competitividad de la miel natural nicaragüense al mercado centroamericano, 2007-2013, tesis de maestría, Universidad Nacional Agraria, Nicaragua.

------ y C. Guido. 2007. Estudio de competitividad y exploración del mercado internacional para miel natural nicaragüense, 2002-2006, tesis de licenciatura, Universidad Nacional Agraria, Nicaragua.

Güemes, J., C. Echazarreta y R. Villanueva. 2002. Condiciones de la apicultura en Yucatán y del mercado y sus productos, México, disponible en: http://www.miel.uqroo.mx/ princip/ensayoyuc.htm (mimeo).

Instituto Boliviano de Comercio Exterior. 2012. Perfil de mercado Miel, disponible en: www.ibce.org.bo/images/estudios_mercado/perfil_ mercado_miel.pdf

Instituto Interamericano de Cooperación para la Agricultura. 2005. La 
competitividad de las cadenas agroproductivas en Colombia, Ministerio de Agricultura y Desarrollo Rural, Colombia.

Kasmier, Leonard J. 2006. Estadística aplicada a la administración y a la economía, 4a edición, Mcgraw-Hill, México.

Kruggman R., Paul. 2004. Economía internacional: teoría y política, Madrid, Pearson Educación, 5a. edición.

-----. 1997. El internacionalismo "moderno". La economía internacional y las mentiras de la competitividad, Barcelona, Crítica.

Lema, D. y Delgado, G. 2000. Productividad y fuentes de eficiencia técnica en apicultura: estimación de fronteras estocásticas de producción con datos de panel. Disponible en https://inta.gob.ar/sites/default/ files/script-tmp-apicultura.pdf (mimeo).

Macías Macías, Alejandro. 2010. Competitividad de México en el mercado de frutas y hortalizas de Estados Unidos de América, 1989-2009, Agroalimentaria, 16(31): 31-48.

Magaña Magaña, M.A., A. Aguilar, P. Lara y J.R. Sanginés. 2007. Caracterización socioeconómica de la actividad apícola en el estado de Yucatán, México, Agronomía, 15 (2): 17-24.

-, J.R.Sanginés, P. Lara, L. Salazar y C. Leyva. 2017. Competitividad y participacion de la miel mexicana en el mercado mundial, Revista Mexicana de Ciencias Pecuarias, 8(1): 43-52, disponible en: http:// cienciaspecuarias.inifap.gob. mx/index.php/ Pecua rias/article/ view/4304.

, Y. Moguel, J.R. Sanginés y C. Leyva. 2012. Estructura e importancia de la cadena productiva y comercial de la miel en México, Revista Mexicana de Ciencias Pecuarias, 3(1): eneromarzo, disponible en: www.scielo.org.mx/scielo.php? pid= S2007112420120001000 04\&script=sci_arttext.

Ministerio de Agricultura y Desarrollo Rural. (sin fecha). Observatorio de agrocadenas Colombia. Metodología de calculo de indicadores de competitividad, Colombia, disponible en: http://bibliotecadigital. 
agronet.gov.co/bitstream/11348/5207/1/2005 112115175_Indicadores $\% 20$ de $\% 20$ competitividad_Observatorio.pdf

Organización de las Naciones Unidas para la Alimentación y la Agricultura (FAO). 2013. Base de datos estadísticos en relación con la alimentación y agricultura (FAOSTAT). disponible en: http:// faostat3.fao.org/download/Q/QL/S, consultado 12 de diciembre de 2013.

Parkin, Michael y E. Loría. 2010. Macroeconomía. Versión para Latinoamérica, México, Pearson Educación, 9a . edición.

Porter, Michael. 2008. "Estrategia competitiva: Técnicas para el análisis de los sectores industriales y de la competencia". Grupo Editorial Patria. México.

Roldán Luna, Diego. 2000. Los indicadores en el contexto de los acuerdos de competitividad de las cadenas productivas, Serie competitividad núm. 17, Colección de documentos IICA, disponible en: www. repiica.iica.int/docs/B0118E/B0118e.pdf.

Soto Muciño, Luis, R. Elizarraras e I. Soto. 2017. Situación apícola en México y perspectiva de la producción de miel en el estado de Veracruz, Revista de Estrategias del Desarrollo Empresarial, 3(7): 40-64, disponible en: http:/www.ecorfan.org/spain/ researchjournals/ Estrategias_del_Desarrollo_Empresarial/vol3num7/Revista_de_ Estrategias_del_Desarrollo_Empresarial_V3_N7_5.pdf.

C. Chiatchoua y Y. Castañeda. 2015. National and international panorama of honey production in Mexico, ECORFAN JournalRepublic of Cameroon, 1(1): 15-33.

Villegas, G., A. Bolaños, J. Miranda y A. Zenón. 2000. Flora nectarífera y polinifera en el estado de Chiapas, COTECOCA-SAGAR, México. 